\title{
Factors related to adherence to pharmacological treatment of people with type 2 Diabetes Mellitus
}

\author{
Carla Siebra de Alencar ${ }^{1}$, Francisca Diana da Silva Negreiros*1 ${ }^{*}$, Shérida Karanini Paz de Oliveira ${ }^{1}$, Tatiana Rebouças

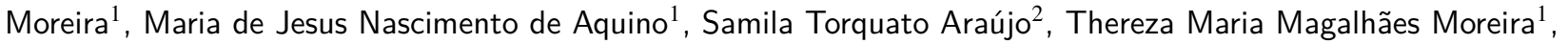 \\ Lucilane Maria Sales da Silva ${ }^{1}$, Ana Célia Caetano de Souza ${ }^{3}$, Francisco Vagnaldo Fechine Jamacaru ${ }^{4}$ \\ ${ }^{1}$ Clinical Care in Nursing and Health Graduate Program, Ceará State University, Fortaleza, Brazil \\ ${ }^{2}$ Public Health Graduate Program, Federal University of Ceará, Fortaleza, Brazil \\ ${ }^{3}$ Diabetes and Obesity Care Center, Federal University of Ceará, Fortaleza, Brazil \\ ${ }^{4}$ Drug Research and Development Center, Federal University of Ceará, Fortaleza, Brazil
}

Received: June 27, 2021

DOI: $10.5430 /$ jnep.v12n2p34
Accepted: September 12, $2021 \quad$ Online Published: September 22, 2021

URL: https://doi.org/10.5430/jnep.v12n2p34

\begin{abstract}
Adherence is a key factor for the treatment of chronic conditions, especially if different drug administration routes are needed. This study aimed to analyze factors associated with adherence to pharmacological treatment in patients with type 2 diabetes. A cross-sectional study was carried out with 173 patients with type 2 diabetes, using a questionnaire with sociodemographic and clinical variables and the Morisky-Green Scale. Multivariate statistics were used. The results show that the female gender (69.4\%), elderly (59.5\%), low education (62.4\%), and ten years or more years of diagnosis $(67.1 \%)$ predominated in the sample. People over 60 years old were more likely to adhere to treatment than young adults (OR: 2.57 ). Those who performed physical activities were more likely to accept treatment than sedentary subjects (OR: 2.04). In conclusion, the study shows a significant association between adherence to pharmacological treatment and the variables age over 60 and physical activity practice.
\end{abstract}

Key Words: Diabetes Mellitus, Type 2, Treatment adherence and compliance, Drug therapy, Self care, Health promotion

\section{INTRODUCTION}

Adherence to treatment is a key factor and particularly important for complex therapies of chronic conditions involving polypharmacy with different dosages and routes of administration such as subcutaneous therapies, which need a longterm administration. ${ }^{[1]}$ Diabetes mellitus (DM) stands out among the chronic conditions and is considered a public health problem of the 21 st century, due to its high incidence and global prevalence. There are 463 million people with DM in the world between 20 and 79 years old. Brazil has the highest prevalence rate in Latin America, with 16.8 million people with diabetes in this same age group. ${ }^{[2]}$

Hyperglycemia is a characteristic of DM, and altered blood glucose in the long term causes chronic complications. Therapeutic interventions aimed at glycemic and metabolic control are needed to prevent or delay the onset of complications. The treatment of DM requires lifestyle changes and pharmacological treatment. Lifestyle changes mean better food choices, regular practice of physical activity, obtaining or maintaining adequate weight, monitoring blood glucose, and using oral antidiabetics and insulin continuously when the other prevention and control measures are exhausted. ${ }^{[3]}$

\footnotetext{
*Correspondence: Francisca Diana da Silva Negreiros; Email: negreiros.diana@gmail.com; Address: Clinical Care in Nursing and Health Program, Ceará State University - 1290 Pastor Samuel Munguba St., Fortaleza, Ceará, Brazil.
} 
Thus, therapeutic adherence is essential to improve glycemic control and requires patient commitment. ${ }^{[4]}$ Adherence means using at least $80 \%$ of the prescribed treatments, observing schedules, doses, and treatment time. Among the factors that can influence treatment adherence are those linked to the treatment, the health condition, the patient, social and economic factors, and factors related to the system and the health team. ${ }^{[5]}$

The main characteristics related to adherence to treatment have been demonstrated in research for many years, as this phenomenon is influenced by numerous aspects of biological, psychological, social, cultural, and economic nature. However, adherence to drug treatment in diabetes is still a problem that deserves further investigation. Thus, it is important for health professionals to know and control these factors to empower the patient for self-care, encouraging acceptance.

This study aimed to analyze the factors associated with the adherence to the pharmacological treatment of people with type 2 diabetes mellitus.

\section{MethodS}

\subsection{Ethical aspects}

The Research Ethics Committee of the University in which the study was undertaken approved the research and followed the ethical principles recommended by Resolution 466/12 of the National Health Council of Brazil, which regulates the guidelines and standards of research with human beings. All participants were informed about the research, read and signed a consent form.

\subsection{Study design, location, and period}

An observational study with a cross-sectional analytical approach was conducted. It is part of the research project called "Evaluation of diabetes mellitus education programs in a referral service", developed in an endocrinology and diabetes service in a University hospital located in Fortaleza, Brazil. Data were collected from June to August 2018. The study followed the guidelines of the EQUATOR network, using the instrument called Strengthening the Reporting of Observational Studies in Epidemiology (STROBE).

\subsection{Population, sample, inclusion and exclusion criteria}

Sample calculation was established for the finite population, with $95 \%$ confidence and 5\% error, considering an estimate of the proportion equal to 50\%. From a population of 313 people with DM2, we included 173 patients in the sample.

The inclusion criteria in the study were people diagnosed with type 2 diabetes mellitus (DM2) who were continuously

Published by Sciedu Press monitored at the referring service, able to understand, verbalize, and answer the questions. We excluded people transplanted with DM2. The choice of participants was for convenience during the follow-up consultation in the study setting. Patients were invited to participate in the research in the outpatient waiting room, with the objective and benefits of the study being presented, among other aspects.

\subsection{Study protocol}

We collected data by applying a questionnaire prepared by the researchers, and performed pre-tests to avoid inconsistencies at the time of collection. The questionnaire had sociodemographic variables (gender, age, skin color, education level, and situation in the job market), clinical data (time since DM diagnosis and associated comorbidities), lifestyle (smoking, use of alcohol, and physical activity), laboratory examination (glycosylated hemoglobin, HbA1c) and aspects related to drug treatment (use of insulin and self-monitoring). For the evaluation of laboratory tests, the parameters of the Brazilian Diabetes Society were considered, ${ }^{[3]}$ which are an $\mathrm{HbAlc} \geq 7 \%$ as altered, obesity having a body mass in$\operatorname{dex}(B M I) \geq 30 \mathrm{~kg} / \mathrm{m}^{2}$, systemic arterial hypertension, the presence of Systolic Blood Pressure (SBP) $\geq 130 \mathrm{mmHg}$ or Diastolic Blood Pressure (DBP) $\geq 80 \mathrm{mmHg}$. For the assessment of dyslipidemia, it was characterized by an increase in triglycerides $(\geq 150 \mathrm{mg} / \mathrm{dL})$, low HDL levels $(\leq 40 \mathrm{mg} / \mathrm{dl})$, and LDL $(\geq 100 \mathrm{mg} / \mathrm{dl})$. The information on clinical data, laboratory tests, and drug treatment were obtained from the medical records.

Treatment adherence was assessed using a modified MoriskyGreen scale, a psychometric scale used to assess adherence to pharmacological treatments of any disease, with 6 (six) items to which the participants respond in a dichotomous way (yes/no), with the answers being scored as yes (concerning adherence, assigned a value of zero) or no (about non-adherence, with the value of one) ${ }^{[6]}$ In this study, the values of 5 (five) and 6 (six) were considered indicative of adherence to treatment, which corresponds to the acceptance of at least $80 \%$ of the prescribed care, as recommended by the Ministry of Health of Brazil. ${ }^{[5]}$

The modified Morisky-Green scale used in the study has good internal consistency, with a Cronbach's $\alpha$ of 0.73 (95\% CI: $0.67-0.79){ }^{[6]}$ Reliability assessed by internal consistency analysis is ideal when Cronbach's $\alpha$ coefficient is greater than 0.7 , but acceptable when it is greater than 0.6. ${ }^{[7]}$

\subsection{Data analysis}

In the analysis, categorical variables were subjected to descriptive statistics, with absolute and relative frequencies. The association of sociodemographic and clinical factors 
(independent variables) and adherence to drug treatment (dependent variable), measured by the Morisky-Green scale, was initially verified by the chi-square, and the strength of association was calculated by determining the odds ratio (OR), adopting the $95 \%$ confidence interval.

Also, the independent variables associated with treatment adherence were selected to integrate the logistic regression model to identify those that, independently, constitute factors associated with adherence. The stepwise backward method was used for removing the variables from the model defined by the Wald test. Such analyses enabled us to determine the adjusted odds ratio, precision (95\% confidence interval), and significance (Wald test) of the estimates. In all analyzes, two-tailed tests were used, considering $p<.05$ as statistically significant. We used the IBM Statistical Package for the Social Sciences (SPSS) software version 23.0 to perform the statistical procedures.

\section{Results}

Regarding the Morisky-Green scale, adherence was considered adequate in patients who scored greater than or equal to five in the six items. Thus, among the 173 participants, $118(68.2 \%)$ had adherence to drug treatment. As for age, the mean was 61.23 ( $\mathrm{SD}=9.6$ ) years old, with the highest age as 93 years old and the lowest as 37 years old, with a predominance of the elderly population $103(59.5 \%)$. Of these, $120(69.4 \%)$ were female, $118(68.2 \%)$ were brown (self-reported skin color), and $108(62.4 \%)$ had $\leq 8$ years of schooling. As for the situation in the labor market, 74 $(42.8 \%)$ were retired, and the monthly income was more than one minimum wage in $118(68.2 \%)$ participants in the study. A total of $116(67.1 \%)$ participants had ten years or more of diagnosis of diabetes. In their life habits, $87(50.3 \%)$ reported being a smoker at some point in life, $88(50.9 \%)$ reported using or having used alcohol, and 91 (52.6\%) did not practice physical activity (see Table 1 ).

Regarding the adherence to pharmacological treatment, we did not observe differences between females and males, neither with education level nor income $(p>.05)$. However, we found that people aged $>60$ years old had better adherence to drug treatment $(p<.05)$ (see Table 2$)$.

As for the comorbidities associated with type 2 diabetes mellitus, we observed that $149(86.1 \%)$ were hypertensive, $141(81.5 \%)$ had dyslipidemia, and 77 (44.5\%) were obese. Regarding the association between clinical characteristics and adherence to pharmacological treatment, there were no differences regarding the variables studied $(p>.05)$, except for the practice of physical activity, in which we observed a better adherence to pharmacological treatment $(p<.05)$ (see
Table 3).

Regarding the chronic microvascular complications, 105 $(60.7 \%)$ the patients had motor sensory neuropathy, and 50 (28.9\%) had diabetic retinopathy. As for the macrovascular complications, 27 (15.6\%) people had peripheral vascular disease, 15 (8.7\%) diabetic foot, 37 (21.4\%) ischemic heart disease, and $12(6.9 \%)$ already had a stroke. No statistically significant correlations were found between complications, adherence to pharmacological treatment, and other variables $(p>.05)$. However, we observed that 75 (71.43\%) patients who presented motor sensory neuropathy as a complication did not have adherence to pharmacological treatment (see Table 4).

Table 1. Sociodemographic and clinical characterization of the patients

\begin{tabular}{|c|c|c|}
\hline Variables & $\mathbf{N}$ & $\%$ \\
\hline \multicolumn{3}{|l|}{ Gender } \\
\hline Female & 120 & 69.4 \\
\hline Male & 53 & 30.6 \\
\hline \multicolumn{3}{|l|}{ Age (years old) } \\
\hline$<60$ & 70 & 40.5 \\
\hline$\geq 60$ & 103 & 59.5 \\
\hline \multicolumn{3}{|l|}{ Skin color } \\
\hline Brown & 118 & 68.2 \\
\hline Other & 55 & 31.8 \\
\hline \multicolumn{3}{|c|}{ Educational level (years) } \\
\hline$\leq 8$ & 108 & 62.4 \\
\hline$>8$ years & 65 & 37.6 \\
\hline \multicolumn{3}{|c|}{ Situation in the labor market } \\
\hline Retired & 74 & 42.8 \\
\hline Unemployed & 18 & 10.4 \\
\hline Sick paid & 20 & 11.6 \\
\hline Others & 61 & 35.2 \\
\hline \multicolumn{3}{|l|}{ Monthly income } \\
\hline$\leq 1^{*}$ & 55 & 31.8 \\
\hline$>1$ & 118 & 68.2 \\
\hline \multicolumn{3}{|c|}{ Diagnostic time (in years) } \\
\hline$<10$ & 57 & 32.9 \\
\hline$\geq 10$ & 116 & 67.1 \\
\hline Smoking & 87 & 50.3 \\
\hline No smoking & 86 & 49.7 \\
\hline Use of alcohol & 88 & 50.9 \\
\hline No use of alcohol & 85 & 49.1 \\
\hline \multicolumn{3}{|l|}{ Physical activity } \\
\hline Active & 82 & 47.4 \\
\hline Inactive & 91 & 52.6 \\
\hline \multicolumn{3}{|l|}{ Acute complications $^{\dagger}$} \\
\hline Hypoglycemia & 84 & 48.6 \\
\hline Diabetic ketoacidosis & 2 & 1.2 \\
\hline Hyperglycemic state & 32 & 18.5 \\
\hline
\end{tabular}

*Minimum wage R\$ 954,00 (Brazilian currency);

${ }^{\dagger}$ Categories are not mutually exclusive; HAS: systemic arterial hypertension 
Table 2. Association between sociodemographic characteristics and the adherence to pharmacological treatment in patients with diabetes mellitus

\begin{tabular}{|c|c|c|c|c|c|c|c|}
\hline \multirow{3}{*}{ Characteristics } & \multicolumn{4}{|c|}{ Treatment adherence } & \multirow{3}{*}{ OR* } & \multirow{3}{*}{$\mathrm{CI}^{\dagger} 95 \%$} & \multirow{3}{*}{$\boldsymbol{p}^{\ddagger}$} \\
\hline & \multicolumn{2}{|c|}{ Present } & \multicolumn{2}{|c|}{ Absent } & & & \\
\hline & $\mathbf{n}$ & $\%$ & $\mathbf{n}$ & $\%$ & & & \\
\hline \multicolumn{8}{|l|}{ Gender } \\
\hline Female & 41 & 34.17 & 79 & 65.83 & 1.45 & $0.71-2.96$ & .313 \\
\hline Male & 14 & 26.42 & 39 & 73.58 & 1 & & \\
\hline \multicolumn{8}{|l|}{ Age (years) } \\
\hline$\geq 60$ & 41 & 39.81 & 62 & 60.19 & 2.65 & $1.31-5.36$ & .006 \\
\hline$<60$ & 14 & 20.00 & 56 & 80.00 & 1 & & \\
\hline \multicolumn{8}{|c|}{ Education level (years) } \\
\hline$>8$ & 22 & 33.85 & 43 & 66.15 & 1.16 & $0.60-2.24$ & .653 \\
\hline$\leq 8$ & 33 & 30.56 & 75 & 69.44 & 1 & & \\
\hline \multicolumn{8}{|l|}{ Monthly income } \\
\hline$\leq 1^{\S}$ & 20 & 36.36 & 35 & 63.64 & 1.36 & $0.69-2.67$ & .378 \\
\hline$>1$ & 35 & 29.66 & 83 & 70.34 & 1 & & \\
\hline
\end{tabular}

*OR: odds ratio; ${ }^{\dagger} \mathrm{CI}$ 95\%: Confidence interval of $95 \%$ of OR; ${ }^{\dagger} p$-value: Significance (Chi-square $p<.05$ ); ${ }^{\S}$ Minimum wage R\$ 954,00 (Brazilian currency).

Table 3. Association between clinical characteristics and adherence to pharmacological treatment in patients with diabetes mellitus

\begin{tabular}{|c|c|c|c|c|c|c|c|}
\hline \multirow{3}{*}{ Characteristics } & \multicolumn{4}{|c|}{ Treatment adherence } & \multirow{3}{*}{$\mathrm{OR}^{*}$} & \multirow{3}{*}{$\mathrm{CI}^{\dagger} 95 \%$} & \multirow{3}{*}{$p^{\ddagger}$} \\
\hline & \multicolumn{2}{|c|}{ Present } & \multicolumn{2}{|c|}{ Absent } & & & \\
\hline & $\mathbf{n}$ & $\%$ & $\mathbf{n}$ & $\%$ & & & \\
\hline \multicolumn{8}{|c|}{ Diagnostic time (years) } \\
\hline$\geq 10$ & 39 & 33.62 & 77 & 66.38 & 1.30 & $0.65-2.60$ & 461 \\
\hline$<10$ & 16 & 28.07 & 41 & 71.93 & 1 & & \\
\hline \multicolumn{8}{|l|}{ Obesity } \\
\hline Yes & 26 & 33.77 & 51 & 66.23 & 1.14 & $0.60-2.18$ & .685 \\
\hline No & 31 & 32.30 & 65 & 67.70 & 1 & & \\
\hline \multicolumn{8}{|l|}{$\mathrm{HbAl} \mathrm{c}^{\S}$} \\
\hline$\geq 7 \%$ & 38 & 31.93 & 81 & 68.07 & 0.99 & $0.42-2.30$ & 972 \\
\hline$<7 \%$ & 10 & 32.26 & 21 & 67.74 & 1 & & \\
\hline \multicolumn{8}{|l|}{$\mathrm{SAH}^{\|}$} \\
\hline Yes & 50 & 33.56 & 99 & 66.44 & 1.92 & $0.68-5.44$ & .214 \\
\hline No & 5 & 20.83 & 19 & 79.17 & 1 & & \\
\hline \multicolumn{8}{|l|}{ Dyslipidemia } \\
\hline Yes & 45 & 31.91 & 96 & 68.09 & 1.03 & $0.45-2.36$ & .942 \\
\hline No & 10 & 31.25 & 22 & 68.75 & 1 & & \\
\hline \multicolumn{8}{|l|}{ Insulin use } \\
\hline Yes & 44 & 33.33 & 88 & 66.67 & 1.36 & $0.63-2.94$ & .435 \\
\hline No & 11 & 26.83 & 30 & 73.17 & 1 & & \\
\hline \multicolumn{8}{|l|}{ Self-monitoring } \\
\hline Yes & 40 & 33.90 & 78 & 66.10 & 1.37 & $0.68-2.77$ & .384 \\
\hline No & 15 & 27.27 & 40 & 72.73 & 1 & & \\
\hline \multicolumn{8}{|l|}{ Physical activity } \\
\hline Active & 33 & 40.24 & 49 & 59.76 & 2.11 & $1.10-4.05$ & .023 \\
\hline Icnative & 22 & 24.18 & 69 & 75.82 & 1 & & \\
\hline
\end{tabular}

*OR: odds ratio; ${ }^{\top} \mathrm{Cl}$ 95\%: Confidence interval of $95 \%$ of OR; ${ }^{\ddagger}$ P-value: Significance (Chi-square $\left.p<.05\right) ;{ }^{\circledR}$ HbAlc: glycated hemoglobin; ${ }^{\text {ISAH: }}$ Systemic Arterial Hypertension. 
Table 4. Association between the presence of chronic complications and adherence to pharmacological treatment in patients with diabetes mellitus

\begin{tabular}{|c|c|c|c|c|c|c|c|}
\hline \multirow{3}{*}{ Characteristics } & \multicolumn{4}{|c|}{ Treatment adherence } & \multirow{3}{*}{ OR* } & \multirow{3}{*}{$\mathrm{CI}^{\dagger} \mathbf{9 5 \%}$} & \multirow{3}{*}{$p^{\ddagger}$} \\
\hline & \multicolumn{2}{|c|}{ Present } & \multicolumn{2}{|c|}{ Absent } & & & \\
\hline & $\mathbf{n}$ & $\%$ & $\mathbf{n}$ & $\%$ & & & \\
\hline \multicolumn{8}{|l|}{ Retinopathy } \\
\hline Yes & 18 & 36.00 & 32 & 64.00 & 1.31 & $0.65-2.62$ & .449 \\
\hline No & 37 & 30.08 & 86 & 69.92 & 1 & & \\
\hline \multicolumn{8}{|l|}{ Nephropathy } \\
\hline Yes & 5 & 20.00 & 20 & 80.00 & 0.49 & $0.17-1.38$ & .171 \\
\hline No & 50 & 33.78 & 98 & 66.22 & 1 & & \\
\hline \multicolumn{8}{|l|}{ Neuropathy } \\
\hline Yes & 30 & 28.57 & 75 & 71.43 & 0.69 & $0.36-1.32$ & .258 \\
\hline No & 25 & 36.76 & 43 & 63.24 & 1 & & \\
\hline \multicolumn{8}{|l|}{$\mathrm{PVD}^{\S}$} \\
\hline Yes & 6 & 22.22 & 21 & 77.78 & 0.57 & $0.21-1.49$ & .245 \\
\hline No & 49 & 33.56 & 97 & 66.44 & 1 & & \\
\hline \multicolumn{8}{|l|}{ Diabetic foot } \\
\hline Yes & 4 & 26.67 & 11 & 73.33 & 0.76 & $0.23-2.51$ & .656 \\
\hline No & 51 & 32.28 & 107 & 67.72 & 1 & & \\
\hline \multicolumn{8}{|c|}{ Ischemic heart disease } \\
\hline Yes & 15 & 40.54 & 22 & 59.46 & 1.64 & $0.77-3.47$ & .197 \\
\hline No & 40 & 29.41 & 96 & 70.59 & 1 & & \\
\hline \multicolumn{8}{|l|}{$\mathrm{CVA}^{\|}$} \\
\hline Yes & 4 & 33.33 & 8 & 66.67 & 1.08 & $0.31-3.75$ & .905 \\
\hline No & 51 & 31.68 & 110 & 68.32 & 1 & & \\
\hline
\end{tabular}

The logistic regression results showed that people over 60 years old were more likely to adhere to treatment than young adults (OR 2.57 95\% CI 1.26-5.24). In general, those who performed physical activities were more likely to adhere to treatment than those who were sedentary (OR $2.0495 \% \mathrm{CI}$ 1.05-3.96) (see Table 5).

Table 5. Determination of factors associated with adherence to pharmacological treatment in patients with diabetes mellitus, after controlling for possible confounding variables

\begin{tabular}{|c|c|c|c|c|}
\hline Factors & Gross odds ratio & Adjusted odds ratio & CI* 95\% & Significance (Wald test) \\
\hline \multicolumn{5}{|l|}{ Age } \\
\hline$\geq 60$ & 2.65 & 2.57 & $1.26-5.24$ & $p=.010$ \\
\hline$<60$ & 1 & 1 & & \\
\hline \multicolumn{5}{|c|}{ Physical activity } \\
\hline Active & 2.11 & 2.04 & $1.05-3.96$ & $p=.036$ \\
\hline Inactive & 1 & 1 & & \\
\hline \multicolumn{5}{|c|}{ Nephropathy } \\
\hline Yes & 0.49 & 0.49 & $0.17-1.43$ & $p=.191$ \\
\hline No & 1 & 1 & & \\
\hline \multicolumn{5}{|c|}{ Ischemic heart disease } \\
\hline Yes & 1.64 & 1.32 & $0.59-2.92$ & $p=.498$ \\
\hline No & 1 & 1 & & \\
\hline
\end{tabular}




\section{Discussion}

The study population was mostly elderly women, with low educational levels since a small portion of the population had more than eight years of schooling, with a family income of up to one minimum wage. These findings were also found in a descriptive study conducted in the city of Colinas, Brazil. ${ }^{[8]}$

Age was an influencing factor in adherence to pharmacological treatment in patients with DM2, and improved adherence was related with increasing age. This finding is consistent with data from a meta-analysis. The advanced age was a mitigating factor in the drug involvement with the elderly 1.13 times more likely than the comparison group to take prescribed drugs. ${ }^{[9]}$

The education level and income did not significantly correlate, diverging from a study in a hospital in Ethiopia with 146 patients, which evaluated adherence to antidiabetic drugs and found a significant association between education level and adherence to treatment. The low educational level has been associated with higher rates of non-adherence since pharmacological therapy over the years and progression of the disease becomes more complex, requiring patients to have cognitive skills to understand the therapy. ${ }^{[10]}$ However, in a national study, the level of education did not directly interfere in adherence to treatment. However, health education proved to be an ally to face the problems arising from the little knowledge of the population, a challenge for the health team, as educational strategies to encourage adherence are needed. ${ }^{[8]}$

A systematic review focusing on factors associated with pharmacological adherence in diabetes indicated that the reasons associated with adherence to the drug treatment in patients with diabetes are multifactorial, with factors related to the patient, age, depression, and literacy level. Side effects and dosing frequency were the most commonly reported drugrelated factors. On the other hand, aspects related to the disease, such as the duration of diabetes, the complexity of the disease, and complications, were rarely addressed. ${ }^{[11]}$

Regarding the clinical characteristics, we observed that the longer the time of diagnosis, the lower the adherence to therapy, but there was no significant correlation between the findings. However, these data are consistent with a crosssectional study carried out in a general hospital in Ethiopia with 275 patients with diabetes. Its objective was to assess the complexity of the medication regimen and its impact on treatment adherence and glycemic control, which showed that patients with less than ten years of treatment had twice as much adherence as the other participants $(\mathrm{OR}=2.619$, 95\% CI: 1.208 to 5.682$).{ }^{[12]}$
This data may be related to the patient's enthusiasm at the beginning of the treatment and the prospect of improvement. However, due to the chronicity of the disease, the continuity and complexity of the treatment may influence long-term persistence and adherence. Corroborating our findings, a study in the United States with 273 patients with diabetes aimed to assess barriers to medication adherence and identified barriers related to young age, low health literacy levels, patient disappointment when the drug does not immediately improve diabetes, and the feeling of exhaustion when taking medication for the illness. It is important to evaluate a comprehensive list of factors to ensure that any barriers are detected for each patient. ${ }^{[13]}$

Ratifying with the data of this study, a randomized clinical trial in the city of Belo Horizonte in Brazil, with 470 people with DM2, aimed to evaluate the effectiveness of an educational program on diabetes mellitus in primary health care and showed that the strategies used in the intervention group contributed to maintaining glycemic control throughout the study. There was also a decrease in the variables related with metabolic control in the intervention group. ${ }^{[14]}$ Nurses are in a key position to help patients in primary health care understand and adhere to their regimens using simple strategies such as using images to teach about prescriptions, the disease, and its complications. Besides, it is necessary to involve the multidisciplinary team in caring for people with diabetes.

Hypertension, dyslipidemia, and obesity were the main comorbidities found. Despite the non-correlation with treatment adherence, we observed that comorbidities associated with diabetes could contribute to non-adherence. This result corroborates the findings of a cross-sectional study carried out in Saudi Arabia with 375 patients, which found that low frequency of comorbidities was significantly related to high adherence. Also, the number of drugs taken usually depends on the severity of DM and the associated comorbidities. This complex treatment regimen can contribute to non-adherence, as people tend to forget to take their medicines. ${ }^{[15]}$

Polypharmacy and multiple medication schedules can be predictive factors for non-adherence to pharmacological treatment. Another study shows that patients with associated comorbidities had a $32 \%$ reduction in the level of adherence $(\mathrm{OR}=0.678,95 \%$ CI: 0.436 to 0.860$){ }^{[16]}$ Polypharmacy needs to be effectively controlled as its incorrect establishment can predispose serious risks to the health of patients with diabetes and, consequently, may increase the rate of non-adherence to the treatment. ${ }^{[16]}$

We observed that most patients had altered HbA1c levels, above the value recommended by the Brazilian Diabetes So- 
ciety $^{[3]}$ and the American Diabetes Association. ${ }^{[17]}$ Despite the statistical insignificance, we verified that adherence was absent or decreased in those with $\mathrm{HbA1c}$ values $\geq 7$. These findings can be correlated with data from a cross-sectional study conducted at the national hospital in Kenya with 290 patients with diabetes, whose objective was to assess pharmacological adherence among patients. A significant association was found between medication adherence and glycemic control. ${ }^{[18]}$

A study confirmed that the good glycemic control of HbAlc $<$ $7 \%$ was greater in patients with high adherence to medication for DM than among those who did not have adherence. ${ }^{[15]}$ The patient may have adherence to one of the elements of treatment and not to others, with a greater tendency to adhere to pharmacological treatment and worse adherence to other components of the treatment, such as healthy eating and physical activity. ${ }^{[19]}$

Physical activity in this study had a significant correlation with treatment adherence; that is, those who were active had greater adherence to pharmacological treatment. Corroborating these findings, a study conducted in Brazil showed that patients who used to practice physical activities at high levels had satisfactory levels of HbA1c. ${ }^{[20]}$ A systematic review aimed to evaluate the effect of different types of exercise on glycated hemoglobin in patients with diabetes and showed a reduction in $\mathrm{HbA1c}$ levels in all training groups, without differences between them. ${ }^{[21]}$

The practice of physical activity proved to be an important intervening factor for good glycemic control and consequent better adherence to treatment. Physical activity is one of the pillars of diabetes treatment, as it has a significant impact on improving glycemic control and preventing associated complications and comorbidities. Regular physical activity is beneficial for anyone. In elderly people, it has great relevance in maintaining lean mass, helping to prevent sarcopenia, and it is also relevant in the cardiovascular aspect. ${ }^{[3]}$

Therefore, the findings showed the importance of changing the lifestyle of people with DM2, as a sedentary lifestyle is a predictor of non-adherence to treatment. Thus, health professionals should encourage and guide their patients about the importance of physical activity and changes in eating habits for a good glycemic control thus empowering patients to acquire knowledge about their health condition, improving treatment adherence.

In short, the role of health professionals is to encourage peo- ple with diabetes of all ages to practice physical activities regularly, progressively, and safely. ${ }^{[3]}$ Health professionals must use educational strategies that enable the person's active participation in the teaching-learning process to obtain behavioral changes necessary for their self-care, reducing the barriers to treatment adherence. ${ }^{[4]}$ Educational interventions with flexible strategies are viable alternatives to make people aware of diabetes care and contribute to the maintenance or reduction of glycated hemoglobin levels and other indicators of metabolic function. ${ }^{[14]}$

In this context, health education must be rescued and recognized as an essential work tool to help people with chronic diseases, especially DM. To ensure the promotion of an effective and comprehensive disease control, capable of achieving the prevention of chronic complications, we need to consider the specificities of the disease and the demands generated by it. ${ }^{[22]}$ In this context, we suggest that educational activities conducted by a multi-professional team can be instituted to strengthen the link between the health team and the patients. ${ }^{[23]}$

\section{Study limitations and implications}

One problem in the study was the absence of a standard instrument to measure pharmacological adherence, as all methods available have disadvantages. Adherence is a selfreported construct, and the subjects may have overestimated their adherence. The convenience sample can also be a limitation of the study.

The findings of our study can serve as a motivator for pratictioners to develop interventions that may increase adherence to diabetes treatment, minimizing disease progression, morbidity and mortality. Furthermore, our study can be a start point of further studies on interventions to improve adherence to diabetes treatment.

\section{Conclusion}

Most participants had treatment adherence behaviors. Also, there was a positive and significant association between adherence to pharmacological treatment and age equal to or above 60 years and physical activity. The research highlights the need to assess adherence to pharmacological treatment in health services to verify the reach and effectiveness of educational actions implemented in these services, especially for patients with DM.

\section{Conflicts OF InTEREST Disclosure}

The authors declare that there is no conflict of interest. 


\section{REFERENCES}

[1] Forbes CA, Deshpande S, Sorio-Vilela F, et al. A systematic literature review comparing methods for the measurement of patient persistence and adherence. Curr Med Res Opin. 2018; 34(9): 161325. PMid:29770718 https : //doi .org/10 . 1080/03007995. 201 8.1477747

[2] International Diabetes Federation (IDF). IDF Diabetes Atlas Ninth Edition 2019 [Internet]. IDF; 2019 [cited 2021 Jun 6]. Available from: https : //www.diabetesatlas.org/en/

[3] Brazilian Society of Diabetes (SBD). Guidelines of the Brazilian Society of Diabetes 2019-2020. SBD; 2019.

[4] Figueira ALG, Boas LCGV, Coelho ACM, et al. Educational interventions for knowledge on the disease, treatment adherence and control of diabetes mellitus. Rev Latinoam Enferm. 2017; 25. PMid:28443992 https : //doi.org/10.1590/1518-8345.1648 .2863

[5] Brazilian Ministry of Health. Synthesis of Evidence for Health Policies: Adherence to Drug Treatment by Patients with Chronic Diseases. Brasília: Brazilian Ministry of Health; 2016.

[6] Ben AJ, Neumann CR, Mengue SS. The brief medication questionnaire and Morisky-Green test to evaluate medication adherence. Rev Saude Publica. 2012; 46(2): 279-89. PMid:22331180 https://doi.org/10.1590/S0034-89102012005000013

[7] Fachel JM, Camey SA. Avaliação psicométrica: qualidade das medidas e o entendimento dos dados. In: Cunha JA. Psicodiagnóstico. Porto Alegre: Artmed; 2000.

[8] Sousa MA, Araújo JL, Corrêa AA. Does the level of education influente the treatment of type 2 diabetic? Rev Prev Infecç Saúde. 2019; 5. https://doi.org/10.26694/repis.v5i0.8965

[9] Choi YJ, Smaldone AM. Factors associated with medication engagement among older adults with diabetes: Systematic review and metaanalysis. The Diabetes Educ. 2018; 44(1): 15-30. PMid:29284354 https://doi.org/10.1177/0145721717747880

[10] Ali M, Alemu T, Sada O. Medication adherence and its associated factors among diabetic patients at Zewditu Memorial Hospital, Addis Ababa, Ethiopia. BCM Res Notes. 2017; 10(1): 676. PMid:29202857 https : //doi .org/10.1186/s13104-017-3025-7

[11] Jaam M, Awaisu A, Ibrahim MI, et al. Synthesizing and Appraising the Quality of the Evidence on Factors Associated with Medication Adherence in Diabetes: A Systematic Review of Systematic Reviews. Value Health Reg Issues. 2017; 13: 82-91. PMid:29073997 https://doi.org/10.1016/j.vhri.2017.09.001

[12] Ayele AA, Tegegn HG, Ayele TA, Ayalew MB. Medication regimen complexity and its impact on medication adherence and glycemic control among patients with type 2 diabetes mellitus in an Ethiopian general hospital. BMJ Open Diabetes Res Care. 2019;
7(1): e000685. PMid:31321061 https://doi.org/10.1136/bm jdrc-2019-000685

[13] Nelson LA, Wallston KA, Kripalani S, et al. Assessing barriers to diabetes medication adherence using the Information-MotivationBehavioral skills model. Diabetes Res Clin Pract. 2018; 142: 374-84 PMid:29879495 https ://doi .org/10.1016/j.diabres . 2018 .05 .046

[14] Torres HDC, Pace AE, Chaves FF, et al. Evaluation of the effects of a diabetes educational program: A randomized clinical trial. Rev Saude Publica. 2018; 52: 8. PMid:29412378 https: //doi.org/10.11606/S1518-8787.2018052007132

[15] Alqarni AM, Alrahbeni T, Al Qarni A, et al. Adherence to diabetes medication among diabetic patients in the Bisha governorate of Saudi Arabia - a cross-sectional survey. Patient Prefer Adherence. 2018; 13: 63-71. PMid:30636871 https://doi .org/10.2147/PPA.S1 76355

[16] Penaforte KL, Araújo ST, Fernandes VO, et al. Association between polypharmacy and the adherence to pharmacological treatment in patients with diabetes. Rev Rene. 2017; 18(5): 631. https : //doi .org/10.15253/2175-6783.2017000500010

[17] American Diabetes Association (ADA). Standards of medical care in diabetes - 2020. Diabetes Care. 2020; 43(Supplement 1): S1 LP-S2. https://doi.org/10.2337/dc20-Sint

[18] Waari G, Mutai J, Gikunju J. Medication adherence and factors associated with poor adherence among type 2 diabetes mellitus patients on follow-up at Kenyatta National Hospital, Kenya. Pan Afr Med J. 2018; 29. PMid:29875963 https ://doi .org/10.11604/pamj . 2018.29.82.12639

[19] Souza JD, Baptista MHB, Gomides DS, et al. Adherence to diabetes mellitus care at three levels of health care. Esc. Anna Nery Rev Enferm. 2017; 21(4). https ://doi.org/10.1590/2177-9 465-ean-2017-0045

[20] Kolchraiber FC, Rocha JS, César DJ, et al. Level of physical activity in people with type-2 diabetes mellitus. Rev Cuid. 2018; 9(2): 2105-16. https://doi.org/10.15649/cuidarte.v9i2.512

[21] Yuing T, Lizana PA, Berral FJ. Hemoglobina glicada y ejercicio: una revisión sistemática. Rev Méd Chile. 2019; 147(4). PMid:31344211 https://doi .org/10.4067/S0034-98872019000400480

[22] Salci MA, Meirelles BHS, Silva DMVG. An insight to prevention of chronic complications of diabetes in the light of complexity. Texto Contexto Enferm. 2018; 27(1). https : //doi .org/10.1590/0104 - 07072018002370016

[23] Gouveia BLA, Sousa MM, Almeida TCF, et al. Beliefs related to insulin use in people with Type 2 Diabetes Mellitus. Rev Bras Enferm. 2020; 73(3). PMid:32321140 https ://doi.org/10.1590/0034 $-7167-2019-0029$ 